\title{
0 trabalho aos olhos de Deus: Laborem exercens faz 30 anos
}

Labor in the eyes of God: Laborem exercens completes 30 years

\section{Élio Estanislau Gasda sj}

Doutor em Teologia pela Pontifícia Universidade Comillas de Madrid, professor de Teologia na Graduação e no Programa de Pós-Graduação da Faculdade Jesuíta de Teologia e Filosofia (FAJE), Belo Horizonte, MG - Brasil, e-mail: gasdasj@hotmail.com

\section{Resumo}

Há uma transformação no mundo do trabalho que veio para ficar. Por um lado está em curso um novo padrão tecnológico que altera o modelo produtivo e, por outro, um novo padrão organizacional que fortalece o poder das empresas e fragiliza o trabalhador. A partir da última crise mundial, esse desequilíbrio entre trabalho e capital provocou uma disparada do desemprego e uma acentuação da precariedade laboral em quase todos os países. Nesse contexto, a comemoração dos trinta anos da publicação da encíclica Laborem exercens é uma oportunidade para refletir sobre o mundo do trabalho a partir das pautas oferecidas por João Paulo II nessa Carta magna sobre o trabalho: o princípio personalista, o primado do trabalho sobre o capital, os direitos dos trabalhador, a espiritualidade do trabalho.

Palavras-chave: Laborem exercens. João Paulo II. Trabalho. Economia. 


\section{Abstract}

There exists a transformation in the world of labor that has come to stay. On one hand, there is in course a new technological standard that modifies the productive model, and on the other hand, a new organizational standard that fortifies the power of the companies and weakens the worker. From the last world-wide crisis, this disequilibrium between labor and capital provoked a sudden rise in unemployment and a heightened level of labor precariousness in almost all the countries. In this context, the commemoration of the thirty years of the publication of the encyclical letter Laborem exercens is an opportunity to reflect on the world of labor from the guidelines offered for John Paul II in this Carta magna on the topic of labor: the personalist principle, the primate labor over capital, the rights of the worker, the spirituality of labor.

Keywords: Laborem exercens. John Paul II. Labor. Economy.

\section{Introdução}

O trabalho talvez seja o âmbito da experiência humana em que a pessoa se depara com todos os polos que configuram sua existência como indivíduo e como ser social. No ano em que a Igreja comemora os trinta anos da encíclica Laborem exercens de João Paulo II, é de fundamental importância recordar e atualizar o ensino social da Igreja sobre o trabalho. Faz parte da evangelização. Vale observar que Laborem exercens também é fruto da comemoração de outra encíclica: os noventa anos de Rerum novarum. Escrita em 1891, é o primeiro texto oficial do magistério pontifício que aborda de forma global os problemas sociais derivados da denominada Civilização do Trabalho, que acompanha a Modernidade. A situação de exploração e miséria vivida pelos trabalhadores no início da Revolução Industrial foi o leitmotiv da Rerum novarum. É a culminação de todo um processo eclesial de tomada de consciência ante a miséria dos operários e de reflexão sobre as grandes transformações sociais a partir da Revolução Industrial.

Nestes 120 anos de existência da DSI, o mundo do trabalho sempre ocupou o centro das atenções. Dentre os diversos elementos que compõem o processo econômico, o trabalho, sem dúvida, é o mais importante. 
O dinamismo que marca o pensamento social do magistério pontifício diante das novas condições tecnológicas, econômicas e políticas tem possibilitado um considerável avanço na sua reflexão.

Também hoje, nesses tempos complexos, fluidos e inseguros da globalização, em que o mundo do trabalho sofre as sequelas das constantes crises econômicas - o desemprego, a precariedade, o ataque permanente contra a legislação trabalhista -, é preciso continuar anunciando a mensagem do Evangelho. Como dimensão fundamental da existência humana, o trabalho está inserido no plano de salvação desde as origens, é essencial para a realização dos direitos humanos e dele depende a concretização do bem comum quando pautado pela solidariedade e pela justiça.

Laborem exercens precisa ser comemorada e atualizada porque nos ajuda a compreender a dimensão antropológica, histórica, ética, ecológica e teológica do trabalho. Trata-se, no fundo, de conferir ao trabalho o sentido que tem aos olhos de Deus e, a exemplo de Cristo, fazer desta atividade um caminho para a concretização do Reino. Em suma, o trabalho tem um valor muito mais amplo do que o conferido pelo pensamento hegemônico materialista.

\section{A contribuição de João Paulo II para a doutrina social da Igreja}

A encíclica Laborem exercens (LE), ${ }^{1}$ juntamente com a Sollicitudo rei socialis (1987) e a Centesimus annus (1991), constitui a trilogia magna do ensino social do magistério de João Paulo II (1978-2004). ${ }^{2}$ Sobram

1 Laborem exercens, em adiante: LE. 0 texto oficial em Acta Apostolicae Sedis LXXIII (1981), p. 577-647, está dividido em cinco capítulos e 27 longos números. 0 texto havia sido preparado para o dia 15 de maio de 1981, data em que se comemoravam os noventa anos da Rerum novarum, mas sua publicação teve que ser adiada por causa do atentado sofrido por João Paulo II na Praça de São Pedro. Por isso, o documento foi assinado em 14 de setembro de 1981. É a reflexão de um intelectual polonês, natural de um país pobre do ex-bloco soviético, que foi trabalhador em sua juventude. Cf.: CAMACHO, 1995, p. 395-396.

2 João Paulo II foi o pontífice que mais dedicou atenção à questão social. Além destas três encíclicas, dezenas de mensagens, alocuções e homilias encontram-se disponibilizadas no site do Vaticano: http://www.vatican. va. Além de Laborem exercens, o interesse especial de João Paulo II pelo tema do trabalho aparece no grande número de cartas, audiências gerais, homilias e discursos. Sua última encíclica social, a Centesimus annus (CA) aborda diversos aspectos específicos sobre o trabalho: desemprego (CA 15); trabalho e propriedade 
motivos para a comemoração da publicação de Laborem exercens: trata-se da contribuição mais importante do magistério sobre o tema do trabalho humano. Em primeiro lugar, essa encíclica permite tomar contato com a nova forma de pensar teologicamente as questões sociais inaugurada pelo Concílio Vaticano II. A reflexão está situada dentro do horizonte da Gaudium et spes (GS), de cuja formulação participou o então bispo de Cracóvia, Karol Wojtyla. A partir deste Concílio, o discurso sobre o valor positivo do trabalho está enquadrado no contexto mais amplo da relação entre a Igreja e a Modernidade, saindo de uma relação de oposição intransigente para uma atitude construtiva de diálogo. Em segundo lugar, João Paulo II tinha claro o contexto histórico de seu pontificado e, quanto ao trabalho, expressa a consciência dos novos problemas e começa a encíclica com um prognóstico:

celebramos o nonagésimo aniversário da Encíclica Rerum Novarum em vésperas de novos adiantamentos nas condições tecnológicas, econômicas e políticas, o que - na opinião de muitos peritos - irá influir no mundo do trabalho e da produção, em não menor escala do que o fez a revolução industrial do século passado (LE 1).

Objetivamente, a "questão dos operários" deixou de ser um "o problema de "classe”, ganhou proporções mundiais, portanto, "deve ser tomado em consideração não apenas o âmbito da classe, mas o âmbito mundial das desigualdades e das injustiças" (LE 2). De fato, as últimas décadas do século XX impulsionaram substanciais mudanças na sociedade. O significado destas mudanças receberam diversas interpretações na literatura sociológica: Sociedade Pós-Industrial (Antonio Négri), Sociedade do Conhecimento (André Gorz), Era da Informação (Manuel Castells), Era do Acesso (Jeremi Rifkin), Modernidade Reflexiva (Ulrich Beck), Modernidade Líquida (Zygmunt Bauman), etc.

(CA 31); trabalho como elemento central da economia (CA 31); dimensão social do trabalho (CA 31-32; 43); direito ao trabalho (CA 47); também denuncia a existência de grandes massas de excluídos do mercado de trabalho e dos trabalhadores em regime de super-exploração (CA 33); aponta as alienações que afetam tanto o consumo como o trabalho (CA 41). 


\section{0 problema antropológico fundamental: a inversão economicista}

No epicentro dessa grande transformação encontra-se o mundo do trabalho. Neste pano de fundo a encíclica constata um problema de caráter antropológico que, em última análise, está na raiz da crise do sentido do trabalho. João Paulo II faz uma denúncia da coisificação do trabalho e do trabalhador, "deste processo de desenvolvimento econômico, que converteu o trabalho humano em mercadoria”, como diz Velasco (1982, p. 24). A primazia do sujeito criador, através do trabalho, sobre o objeto produzido explica o erro antropológico fundamental provocado pelo economicismo: uma inversão antropológica na ordem dos conceitos, isto é, a primazia do "capital" sobre o "trabalho" resultante na alienação da pessoa. Ao identificar o nexo entre os materialismos históricos - o capitalismo liberal foi a premissa histórica da filosofia marxista -, confirma-se que, de fato, o capitalismo realizou, historicamente, essa dramática inversão. O "capital" transformou o "trabalho" em instrumento de acumulação material. A práxis dessa inversão

foi inaugurada com a industrialização, na qual se divisava, em primeiro lugar, a possibilidade de multiplicar abundantemente as riquezas materiais, isto é os meios, perdendo de vista o fim, quer dizer o homem, a quem tais meios devem servir (LE 13).

Segundo João Paulo II, durante todo o período da Civilização Industrial, "o problema do trabalho foi tratado no contexto de um grande conflito "entre o mundo do capital" e "o mundo do trabalho", isto é, entre o grupo dos empresários proprietários dos meios de produção e a multidão de trabalhadores envolvidos na produção (LE 11). Trabalho e capital estão enfrentados e essa oposição gerada pela inversão antropológica é o principal conflito ideológico da sociedade contemporânea (ELLACURÍA, 1982, p. 1008-1024). Portanto, "a crítica do capitalismo e do marxismo é uma conseqüência lógica da afirmação da transcendência do sujeito, que não deve ser instrumentalizado" (VELASCO, 1982, p. 25).

É diante dessa inversão, que provoca a exploração, a escravidão e a alienação, que João Paulo II escreve a LE, para reafirmar em bases 
antropológicas o primado do "trabalho" sobre o "capital", ou seja, para corrigir o erro antropológico economicista:

não há outra possibilidade de superação radical deste erro se não se introduzem mudanças tanto no campo teórico como na prática; mudanças na linha do primado da pessoa sobre as coisas, do trabalho humano sobre o capital (LE 11).

A partir de uma perspectiva antropológica correta, é inadmissível qualquer sistema econômico que, invertendo os términos, submeta o "trabalho" ao "capital", reduzindo-o a instrumento a seu serviço e dividindo os homens que estão detrás desses conceitos. Nesse sentido, a LE é uma proposta de fazer do homem trabalhador o protagonista da sociedade. Especificando o trabalho humano como a chave de leitura essencial da questão social, o pontífice polaco proclama um manifesto para uma nova civilização. É preciso voltar-se ao homem que vive de sua capacidade de trabalho para sair da inversão economicista.

\section{0 homem e o trabalho: a perspectiva personalista}

O trabalho como tema central e o homem como ponto focal são os dois polos sobre os quais se estrutura a LE. O homem é o centro nevrálgico da reflexão no momento de apresentar o trabalho como chave da questão social (SOARES FILHO, 1982; SEGURA, 1987). A afirmação da centralidade da dignidade da pessoa humana caracteriza todo magistério de João Paulo II. ${ }^{3}$ É verdade que LE está centrada sobre o trabalho humano, mas, talvez, seria mais correto dizer que está dedicada "ao homem no vasto contexto desta realidade que é o trabalho" (LE 1). O trabalho não está pensado a partir dos sistemas econômicos, do crescimento da riqueza ou de algum valor abstrato, mas a partir do sujeito que trabalha.

3 Idéia central do pontificado de João Paulo II, anunciado na encíclica Redemptor hominis: "o homem é o caminho da Igreja" (Redemptor Hominis 14). 
O trabalho é um dos contextos mais ricos para captar a complexidade dos condicionamentos e inter-relações que perpassam a existência humana. O discurso está focado sobre o significado do trabalho para o homem e do modo de buscar uma vida mais humana. O trabalho, como problema humano, "ocupa o centro da questão social" (LE 2). A reflexão sobre o trabalho exige, portanto, uma antropologia "personalista” em cujo núcleo encontra-se o conceito de "pessoa". ${ }^{4}$ A pessoa e sua dignidade constituem o fundamento de toda práxis. O trabalho é uma realidade especificamente humana, "é uma das características que distinguem o homem das demais criaturas" (LE, Prólogo).

Mas não basta afirmar que o trabalho é uma atividade essencialmente humana. É preciso dar mais um passo e descobrir sua essência mais profunda. O conceito judaico-cristão de homem surge de sua especial referência a Deus. Essa antropologia surge dos primeiros textos bíblicos e recebe toda sua luz na pessoa de Jesus Cristo. Partindo do princípio de que a Igreja deduz suas convicções "sobre tudo da Palavra de Deus revelada”, e leva em consideração as ciências humanas (LE 4), o pontífice funda no relato do Gênesis a ideia de que "o sujeito do trabalho é sempre a pessoa humana 'imagem de Deus', um ser subjetivo capaz de obrar de maneira programada e racional, capaz de autodeterminação e que busca sua realização" (LE 6).

O valor primordial do trabalho está vinculado ao fato de que quem o executa é uma pessoa e toda pessoa é criada à imagem e semelhança de Deus.

\section{"Dominar" a criação, não a pessoa}

A Sagrada Escritura afirma que "o homem é imagem de Deus, entre outros motivos, pelo mandato recebido do Criador de submeter e dominar a terra". O trabalho é um meio que permite tal "domínio". Mas não só. O homem é imagem de Deus pelo mandato recebido do seu Criador

4 WOJTYLA, K. Persona y acción. Madrid: BAC, 1982. Publicado em 1969 (Cracóvia), é o seu principal escrito filosófico, em que apresenta seu ponto de vista sobre a pessoa como sujeito da moral. Como o próprio título indica, personalidade e ação estão relacionadas, pois a ação humana permite compreender a pessoa de um modo mais completo. 0 mistério da pessoa se expressa em seu agir. 
de dominar a terra (Gn 1, 26-28). ${ }^{5}$ No desempenho de tal mandato todos os seres humanos refletem a própria ação do Criador do universo: "todos e cada um, em medida adequada e num número incalculável de modos, tomam parte em tal processo gigantesco, mediante o qual o homem 'submete a terra' com o seu trabalho" (LE 4).

O pensamento bíblico conduz, inevitavelmente, à seguinte conclusão: o homem deve "dominar" o trabalho, e não ser "dominado" pelo trabalho, porque o trabalho é para que o homem "domine" a terra. Para que a "domine", o homem deve, primeiramente, "dominar" seu próprio trabalho. A isto se relaciona uma conclusão de natureza ética: "embora seja verdade que o homem está destinado e é chamado ao trabalho, antes de tudo o trabalho é "para o homem" e não o homem "para o trabalho" (LE 6). É a afirmação do primado da pessoa sobre a organização do trabalho e sobre os bens econômicos produzidos. Primado que, por si só, já implica uma ruptura com as teorias e sistemas economicistas. As diversas formas históricas de dominação do homem sobre outros homens se explicam pela inversão desse princípio.

\section{A preeminência e perenidade do sentido subjetivo}

Da essência mais profunda do trabalho humano emergem seus sentidos objetivo e subjetivo. Ambas as expressões significam a mesma ação de trabalhar com todas as suas implicações, condicionamentos e elementos configuradores. Primeiramente, o sentido objetivo (LE 5). A reflexão gira em torno do aspecto técnico-científico do trabalho que "encontra sua expressão nas várias épocas da cultura e da civilização". Portanto, "quando

5 'Sob a designação 'terra', de que fala o texto bíblico, deve entender-se primeiro de toda aquela parcela do universo visível em que o homem habita; por extensão, porém, pode entender-se todo o mundo visível, na medida em que este se encontra dentro do raio de influência do homem e da sua procura de prover as próprias necessidades. A expressão ‘submeter a terra' tem um alcance imenso. Ela indica todos os recursos que a mesma terra (e indiretamente o mundo visível) tem escondidos em si e que, mediante a atividade consciente do homem, podem ser descobertas e oportunamente utilizadas por ele. Assim, tais palavras, postas logo ao princípio da Bíblia, jamais cessam de ter atualidade. Elas abarcam igualmente todas as épocas passadas da civilização e da economia, bem como toda a realidade contemporânea, e mesmo as futuras fases do progresso, as quais, em certa medida, talvez se estejam já a delinear” (LE 6).

Rev. Pistis Prax., Teol. Pastor., Curitiba, v. 3, n. 2, p. 653-669, jul./dez. 2011 
se considera o trabalho em sentido objetivo se atende fundamentalmente à variedade e riqueza de matizes que essa ação pode adotar, segundo os casos e circunstâncias históricas" (GARCÍA, 1982, p. 139). Tal é o caso da Civilização Industrial, em que o trabalho se mostra cada vez mais mecanizado e tecnológico. Nesse contexto, segundo o pontífice,

É preciso abordar de maneira nova o problema do trabalho humano, pois, mesmo que possa parecer que a máquina "trabalhe", "o sujeito próprio do trabalho segue sendo o homem", pois também a técnica, esse "conjunto de instrumentos dos quais o homem se vale em seu trabalho", resulta do trabalho [...], todavia, considerando os seus sentidos objetivos, tem de se reconhecer que existem muitos trabalhos: um grande número de trabalhos distintos (LE 8).

A abordagem do sentido objetivo conclui com uma advertência: a exaltação da máquina pode "reduzir o homem a ser seu escravo", pervertendo a essência mais profunda do trabalho humano: o homem, "dominado" por seu trabalho (a técnica), já não pode "dominar a terra". Por outro lado, "quando essa mesma ação de trabalhar se considera em seu sentido subjetivo, não se pode esquecer nunca que, sempre e necessariamente, remete e exige que se tenha em conta seu sujeito humano" (GARCÍA, 1982, p. 139). Por esta razão, é de fundamental importância reafirmar o primado do sentido subjetivo do trabalho sobre o sentido objetivo, pois "as fontes da dignidade do trabalho devem ser buscadas principalmente em sua dimensão subjetiva" (LE 6). Esta insistência está motivada pelo fato de que a sociedade contemporânea valoriza de modo quase exclusivo o aspecto objetivo, fruto da evolução da Civilização do Trabalho. O fundamento último do sentido subjetivo do trabalho está na tradição bíblica:

O homem deve submeter a terra, deve dominá-la, porque, como "imagem de Deus", é uma pessoa; isto é, um ser dotado de subjetividade, capaz de agir de maneira programada e racional, capaz de decidir de si mesmo e tendente a realizar-se a si mesmo. É como pessoa, pois, que o homem é sujeito do trabalho. É como pessoa que ele trabalha e realiza diversas ações que fazem parte do processo do trabalho (LE 6). 
O acento não está tanto no "domínio" da natureza quanto na atividade subjetiva do homem e sua realização como pessoa em seu trabalho. Para João Paulo II, "este domínio, num certo sentido, refere-se à dimensão subjetiva ainda mais do que à objetiva: esta dimensão condiciona a mesma natureza ética do trabalho" (LE 6). O fato de que o sentido objetivo do trabalho seja de caráter circunstancial e o sentido subjetivo de caráter perene, está confirmado pelo conteúdo nuclear do cristianismo:

aquele que, sendo Deus, se tornou semelhante a nós em tudo (Heb 2,17, Flp 2, 5-8), [e passou] a maior parte dos anos da vida sobre a terra junto de um banco de carpinteiro, dedicando-se ao trabalho manual. Esta circunstância constitui por si mesma o mais eloqüente "evangelho do trabalho"; aí se torna patente que o fundamento para determinar o valor do trabalho humano não é em primeiro lugar o gênero de trabalho que se realiza, mas o fato de aquele que o executa ser uma pessoa (LE 6).

Isso significa que "o primeiro fundamento do valor do trabalho é o mesmo homem, o seu sujeito” (LE 6). A distinção entre o aspecto subjetivo e objetivo do trabalho com o primado do primeiro, nega a distinção economicista de Adam Smith entre trabalho produtivo e trabalho improdutivo. ${ }^{6}$ A encíclica não nega a necessidade de organizar e estruturar a economia, o que faz é recordar que, em última análise, o fim da economia e do trabalho deve ser sempre a pessoa: o valor do trabalho "se mede, sobretudo pelo padrão da dignidade do mesmo sujeito do trabalho, isto é, da pessoa, do homem que o executa". A pessoa do trabalhador é mais valiosa que o produto do seu trabalho.

Em suma, não se pode separar a dimensão objetiva do trabalho de sua dimensão subjetiva, porque ambas se encontram articuladas em qualquer ação humana. A exaltação do sentido objetivo leva ao esquecimento do trabalhador como sujeito. De modo que o critério para um juízo ético do mundo do trabalho não pode ser outro que a dignidade humana. Desse primado do sentido subjetivo se vislumbram as seguintes consequências éticas para todo e qualquer sistema de produção.

6 Em uma economia de mercado toda a sociedade está orientada para a produtividade e o consumo. 0 trabalho está organizado em função dessa orientação. Aqui, entenda-se trabalho como trabalho produtivo.

Rev. Pistis Prax., Teol. Pastor., Curitiba, v. 3, n. 2, p. 653-669, jul./dez. 2011 


\section{0 primado do trabalho sobre o capital}

Este postulado, que pertence ao conjunto da moral social, tem importância chave tanto em um sistema baseado sobre o princípio da propriedade privada dos meios de produção como no sistema em que esteja limitado, inclusive radicalmente, a propriedade privada dos meios de produção (LE 15).

Tal princípio encontra sua justificativa no primado a que o sentido subjetivo conduz, necessariamente, ao primado do "trabalho" sobre o "capital" (LE 12). O conceito "trabalho" recebe, além dos sentidos analisados até este ponto, uma enorme riqueza de conteúdo. LE faz alusão já em suas primeiras palavras:

é o meio de procurar-se o pão quotidiano e contribuir para o progresso contínuo das ciências e da técnica, e, sobretudo para a incessante elevação cultural e moral da sociedade, na qual vive em comunidade com os próprios irmãos... é todo tipo de ação realizada pelo homem independentemente de suas características ou circunstâncias (LE, Prólogo).

"trabalho" entendido sem reducionismos culturais, ideológicos ou religiosos, pois "se trata de um conceito que "tem múltiplo sentido" e está constituído de forte sentido social [...] "é um sinal da pessoa ativa no meio de uma comunidade de pessoas; este sinal determina sua característica interior e constitui, em certo sentido, sua natureza" (LE 16).

É possível que a adoção de um conceito tão amplo de "trabalho" esteja na mesma linha do projeto da encíclica de "libertar" o trabalho de seu sentido puramente economicista imposto pela inversão antropológica. No conceito de "capital", por sua vez, a encíclica inclui:

tudo que serve ao trabalho, tudo que constitui - no estado atual da técnica- seu "instrumento" cada vez mais aperfeiçoado [...] esse gigantesco e poderoso "instrumento" que é o "conjunto dos meios de produção, que são considerados, em certo sentido, como sinônimos de "capital". São os recursos naturais postos à disposição do homem e o conjunto dos meios com os quais o homem se apropria deles transformando-os segundo suas 
necessidades, o conjunto de meios de produção, desde os mais primitivos até os ultramodernos (LE 12).

Os dois conceitos nos conduzem às seguintes conclusões. Em primeiro lugar, o "capital" constitui um elemento imprescindível da realidade do "trabalho": "não se pode separar o 'capital' do 'trabalho', e menos ainda contrapor o 'trabalho' ao 'capital' nem o 'capital' ao 'trabalho'” (LE 13). Em segundo lugar, nos leva a estabelecer o princípio da prioridade do "trabalho" ante o "capital" (LE 12). "Capital", que são todos os instrumentos de trabalho, todos os meios de produção, desde os mais primitivos até as novas tecnologias, são fruto do trabalho humano. O "capital", que serve ao "trabalho", é fruto do patrimônio histórico da humanidade. Logo, tudo o que serve ao "trabalho" é fruto do "trabalho". Se trata da "tradução, em termos econômicos, do princípio ético do primado das pessoas sobre as coisas". A conclusão apresentada no último parágrafo do n. 12 é de uma coerência notável com toda a reflexão desenvolvida sobre a articulação entre "capital" e "trabalho": "o primeiro é simplesmente um conjunto de coisas", enquanto o segundo, "como atividade de seres humanos, participa da dignidade da pessoa" (LE 12).

\section{A propriedade - privada ou coletiva - a serviço do trabalho}

Embora a LE não ofereça propriamente um conceito de propriedade, proporciona uma série de reflexões sobre o seu sentido ético. Em primeiro lugar, é preciso considerar que "com o trabalho permanece igualmente ligado, desde o princípio, o problema da propriedade" (LE 12), de modo que "o direito de propriedade seja interpretado no amplo contexto do direito comum de todos a usar os bens da criação" (LE 14). Em segundo lugar, a relação entre trabalho e propriedade se estabelece em função do seguinte princípio: "a propriedade se adquire antes de tudo mediante o trabalho e para que sirva ao trabalho" (LE 14). É importante fazer uma distinção entre a apropriação dos recursos naturais e a propriedade dos meios de produção. Quanto à propriedade dos meios de produção, 
o único título legítimo para sua posse é que sirva ao trabalho; em conseqüência, servindo ao trabalho, tornem possível a realização do princípio anterior, que é o destino universal dos bens e o direito ao seu uso comum (LE 14).

Em síntese, João Paulo II não deixa margem a dúvidas de que o magistério social nunca defendeu o direito de propriedade como absoluto e intocável, ao contrário, está subordinado ao direito de uso comum e ao destino universal dos bens; Do ponto de vista ético, os bens nunca podem ser possuídos contra o trabalho; seu uso legítimo somente se justifica para que sirva ao trabalho. Esta doutrina se completa com a insistência na necessidade da crescente participação dos trabalhadores na propriedade e gestão da empresa (LE 14).

\section{Os direitos do trabalhador}

Do sentido subjetivo emanam os direitos do trabalhador:

Se o trabalho - nos diversos sentidos da palavra - é uma obrigação, isto é, um dever, ele é também fonte de direitos para o trabalhador. Tais direitos devem ser examinados no vasto contexto do conjunto dos direitos do homem, direitos que lhe são conaturais [...] os direitos humanos que brotam do trabalho entram precisamente dentro do amplo contexto dos direitos fundamentais da pessoa (LE 16).

É importante considerar que os direitos do trabalhador apresentados nessa encíclica se inserem no contexto de uma economia capitalista do fim do século XX: emprego, salário justo, seguridade social, descanso, greve, sindicalização, direitos da mulher trabalhadora, promoção do trabalho agrícola, direitos do trabalhador com necessidades especiais e o trabalhador migrante (LE 16-23). São direitos inalienáveis e fundamentais em uma sociedade do trabalho assentada na relação salarial. Entretanto, a necessidade de ordenar eticamente a sociedade segundo o princípio do primado do trabalho sobre o capital exige que se avance na busca de um modelo econômico que melhor responda a esse princípio. Enquanto 
subsistam as relações atuais entre "capital" e "trabalho", os direitos enumerados devem ser assegurados e ampliados.

\section{Dimensão teológico-espiritual}

O sentido subjetivo do trabalho revela a dimensão última da pessoa humana: a abertura à transcendência. $\mathrm{Na}$ realidade do homem como sujeito está implícita uma espiritualidade do trabalho. E para apresentá-la, João Paulo II recupera os elementos teológicos desenvolvidos desde a encíclica Rerum novarum e os aplica à espiritualidade em forma de síntese, nos quatro últimos parágrafos de LE (LE 25-27): o homem, criado à imagem e semelhança de Deus, participa de sua obra criadora; tem em Cristo, o homem do trabalho e anunciador do Reino, seu ponto de referência. ${ }^{7}$

LE alude ao tema da "imagem" citando Gaudium et spes n. 34 para mostrar como a atividade humana, ordenada ao bem da humanidade, responde ao plano original de Deus e à vocação humana, completando o plano divino sobre a criação (LE 25). LE cita Gaudium et spes n. 35 para referir-se ao trabalho como um "bem árduo" por meio do qual o homem chega à autorrealização. Ao referir-se ao trabalho à luz da cruz e da ressurreição de Cristo, LE se apoia em GS n. 38. Cada um, seguindo o exemplo de Cristo, faz do seu trabalho um caminho de perfeição e colabora no plano de salvação por meio do amor como atitude que orienta toda a existência (LE 26).

Por último, LE cita Gaudium et spes n. 39 para aproximar a realidade do progresso da sociedade ao crescimento do Reino de Deus. São desenvolvimentos são distintos, mas não opostos. A estreita relação entre eles se realiza pela fé que nos aponta a dimensão escatológica do Reino (LE 26). Essa esperança deve comprometer os fiéis no labor de melhorar a realidade presente, pois o compromisso com a transformação das realidades terrenas é preparação do "material do reino dos céus". O aspecto árduo

7 Praticamente todo o capítulo V de LE é uma reprodução do texto que GS dedica ao sentido da atividade humana no mundo, com exceção dos números reservados, respectivamente, à autonomia das realidades temporais e ao pecado (GS 36-37).

Rev. Pistis Prax., Teol. Pastor., Curitiba, v. 3, n. 2, p. 653-669, jul./dez. 2011 
do trabalho recebe seu sentido na Páscoa de Jesus, pois sua cruz venceu todos os poderes deste mundo.

Essa espiritualidade do trabalho ensina que as muitas e grandes dificuldades do mundo do trabalho não o impossibilitam como um meio de transcendência. A nova terra e os novos céus, o Reino de Deus, representam a meta para a qual devem ser dirigidos todos os esforços por transformar o mundo. O mundo do trabalho é um lugar imprescindível para assumir este compromisso com a transformação da sociedade à luz do Reino (LE 27). Enfim, os elementos teológicos apresentados ao fim da encíclica, em harmonia com o Concílio Vaticano II, conferem um plus de sentido a toda reflexão sobre o trabalho desenvolvida pelo magistério pontifício até o presente momento.

\section{Que se descubram novos significados do trabalho humano (LE 2)}

A amplitude e a complexidade do mundo do trabalho envolvem a antropologia, a política, o direito, a cultura, a economia e a teologia. Somente assumindo esse sentido amplo é possível compreender a tese de João Paulo II de que o trabalho é a chave da questão social (LE 2). Considerar o trabalho unicamente em seu sentido econômico é mutilá-lo em sua essência e reduzi-lo a uma tarefa ou instrumento sem mais. Para compreendê-lo em toda sua profundidade, é preciso "libertá-lo" das ataduras da inversão economicista denunciada em Laborem exercens. De fato, esse desafio de "libertar" o trabalho do economicismo está implícito no enfoque da Doutrina Social da Igreja desde Rerum novarum, seu documento inaugural.

Diante da realidade atual do mundo do trabalho - globalizado, escasso, flexível, precário, imaterial, cognitivo, biopolítico - o imperativo ético da "libertação" do trabalho continua vigente. O esforço de buscar novos significados à atividade humana deve continuar (LE 2). Um trabalho não mais refém dos interesses financeiros, da competitividade selvagem entre as empresas e da irresponsabilidade ambiental. Pensar um trabalho que seja verdadeiramente humano e que liberte as potencialidades 
das pessoas para a criatividade e a solidariedade no cuidado e cultivo da Criação (Gen 2, 15).

No mundo do trabalho está em jogo a dignidade humana e sua liberdade inviolável. A liberdade é um dom ameaçado, mas também um valor a ser conquistado e garantido a cada dia. O jugo da lei do economicismo materialista representa uma verdadeira escravidão para os trabalhadores de hoje. O povo de Israel, que começou com aquela experiência de libertação de um grupo de trabalhadores submetidos ao trabalho forçado (Ex 1,11-14), termina com o cumprimento da promessa da plena libertação, a irrupção do Reino e o descanso em Deus (Heb 4,10-11).

A Doutrina Social da Igreja, através de documentos memoráveis como Laborem exercens, é um chamado permanente para que o compromisso dos cristãos no mundo do trabalho seja inspirado pela experiência da libertação do êxodo de Israel, pela libertação plena da cruz de Cristo, para que toda a família humana seja conduzida à autêntica liberdade dos filhos de Deus: "é para sermos verdadeiramente livres que Cristo nos libertou. Permanecei, pois, firmes e nos vos deixeis oprimir de novo pelo jugo da escravidão" (Gal 5,1).

\section{Referências}

CAMACHO, I. Doutrina social da igreja: una aproximación histórica. São Paulo: Paulinas, 1995.

DÍAZ SÁNCHEZ, J. M. A los veinte años de la encíclica Laborem exercens. Sociedad y Utopía, Madrid, v. 18, p. 53-61, 2001.

ELLACURÍA, I. Conflicto entre capital y trabajo: un punto clave de la Laborem exercens. Estudios Centroamericanos, San Salvador, v. 37, p. 1008-1024, 1982.

GARCÍA, M. Conceptos claves de la Laborem exercens. Fomento Social, Madrid, n. 146, p. 135-144, 1982.

JOÃO PAULO II. Laborem exercens. 1981. p. 577-647. Acta Apostolicae Sedis LXXIII. 
SEGURA, A. ¿Qué significa "persona” en la encíclica Laborem exercens de Juan Pablo II? In: FERNÁNDEZ RODRÍGUEZ, F. Estudios sobre la Encíclica Laborem exercens. Madrid: BAC, 1987. p. 165-184.

SOARES FILHO J. O trabalho humano à luz da encíclica Laborem exercens. Revista Eclesiástica Brasileira, Petrópolis, v. 42, p. 528-550, 1982.

VELASCO, D. Claves de la interpretación de la encíclica Laborem exercens. Corintios XIII, Madrid, v. 27, p. 17-30, 1982.

WOJTYLA, K. Persona y acción. Madrid: BAC, 1982.

Recebido: 17/12/2010

Received: 12/17/2010

Aprovado: 19/01/2011

Approved: 01/19/2011 